\title{
Perspective
}

PERSPECTIVE Actualité en histoire de l'art

Comptes rendus | 2009

\section{Bernard Vouilloux, Un art sans art: Champfleury et les arts mineurs, Lyon, Fage, 2009}

\section{Emmanuel Pernoud}

\section{OpenEdition}

\section{Journals}

Édition électronique

URL : http://journals.openedition.org/perspective/2683

DOI : $10.4000 /$ perspective. 2683

ISSN : 2269-7721

\section{Éditeur}

Institut national d'histoire de l'art

\section{Référence électronique}

Emmanuel Pernoud, «Bernard Vouilloux, Un art sans art : Champfleury et les arts mineurs, Lyon, Fage $2009 »$, Perspective [En ligne], Comptes rendus, mis en ligne le 02 août 2013, consulté le 01 octobre 2020. URL : http://journals.openedition.org/perspective/2683 ; DOI : https://doi.org/10.4000/ perspective.2683

Ce document a été généré automatiquement le 1 octobre 2020. 


\section{Bernard Vouilloux, Un art sans art: Champfleury et les arts mineurs, Lyon, Fage, 2009}

Emmanuel Pernoud

\section{RÉFÉRENCE}

Bernard Vouilloux, Un art sans art : Champfleury et les arts mineurs, Lyon, Fage, 2009. 
Relire Champfleury: tel pourrait être le sous-titre de cette étude. L'œuvre de cet ami de Baudelaire et de Courbet, dont la silhouette apparaît dans L'Atelier du peintre aux côtés d'un enfant qui dessine, est prolifique, fruit d'un travail d'érudition et d'archéologie que son auteur voulait opposer au dilettantisme des esthètes et des amateurs incarnés par les frères Goncourt. Images populaires, caricatures, assiettes décorées: ce n'est pas «l'art pour l'art» mais «l'art sans art », celui des sans voix et des sans grades, qui motivait le combat d'un homme constamment animé par le «sentiment populaire » contre l'art des élites, et par un culte de la naïveté qu'il partagea avec bien d'autres tout en se gardant avec une lucidité prémonitoire de la naïveté autoproclamée des modernes («on n'apprend pas la naïveté » écrit-il dans son Histoire de l'imagerie populaire, en 1869). Au terme d'une analyse aiguë portant sur les textes, sur les illustrations qui les accompagnent et sur le rapport que les uns et les autres entretiennent dans les ouvrages publiés par cette figure singulière de la littérature artistique du XIX ${ }^{\mathrm{e}}$ siècle, Bernard Vouilloux parvient à dégager le « système » Champfleury - au demeurant très peu systématique et fréquemment sujet aux contradictions, comme ne manque pas de le signaler l'auteur. Il montre comment Champfleury poursuit moins une histoire des images qu'une histoire par l'image, en se dotant à cet effet d'une méthode fondée sur l'analogie. Abondamment illustré, ponctué par des citations de Champfleury qui constituent une utile anthologie de ses textes, ce livre est une précieuse contribution à l'histoire d'une alternative esthétique qui donna le jour, un siècle plus tard, à la notion d'Art brut.

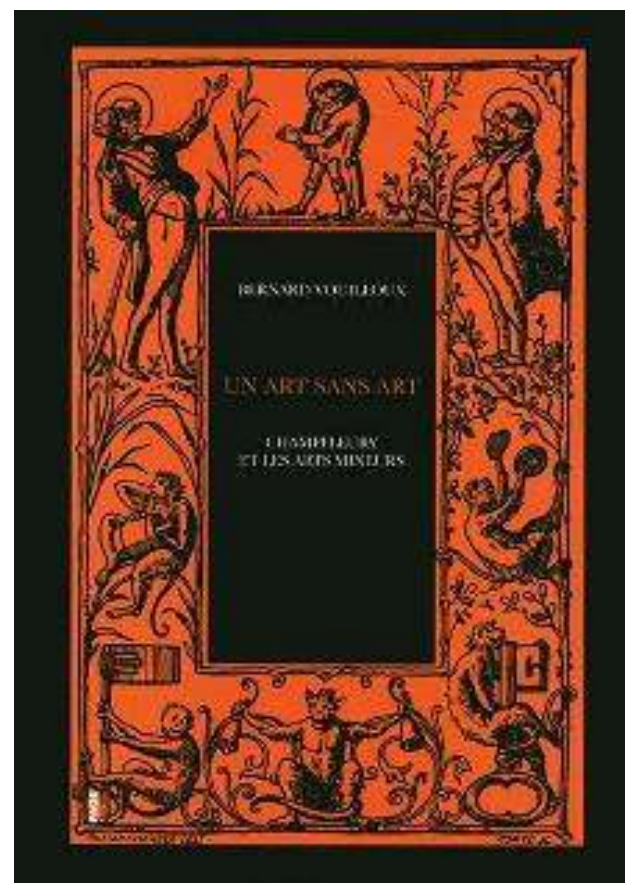

